\section{As emendas parlamentares no orçamento federal da saúde}

\author{
Congressional amendments to the Brazilian \\ Federal health budget
}

\begin{abstract}
The public budget in Brazil has undergone significant changes since enactment of the 1988 Federal Constitution. Mechanisms for integration of planning activities and budget execution have been created, and Legislative participation in budgeting has increased. Congressional amendments appeared in this context. The article discusses the participation of Congressional amendments in the Federal health budget from 1997 to 2006, combining elements for discussion of funding mechanisms and health planning. Such amendments played a significant role in the budget process, accounting for over half of health funds in some years. The North was the region of Brazil that received most resources resulting from Congressional amendments, suggesting the need for further studies on the relationship between the amendments' enforcement and political party coalitions. The article concludes that the amendments cannot be understood solely as a funding mechanism, but mainly as a political instrument, and that they are not necessarily subject to health planning logic.
\end{abstract}

Health Policy; Health Financing; Budgets
Tatiana Wargas de Faria Baptista 1

Cristiani Vieira Machado 1

Luciana Dias de Lima 1

Marcia Garcia 1

Carla Lourenço Tavares de Andrade 1

Camila Duarte Gerassi 1

\section{Introdução}

A Constituição Federal de 1988 introduziu mudanças importantes no orçamento federal com a instituição de mecanismos que buscaram uma maior integração entre o planejamento e o orçamento estatal 1, como o Plano Plurianual (PPA), a Lei de Diretrizes Orçamentárias (LDO) e a Lei Orçamentária Anual (LOA), visando aprimorar o direcionamento dos gastos e melhorar a eficiência na utilização de recursos. Além disso, foram definidas novas formas de participação do Poder Legislativo no processo orçamentário, como a possibilidade de apresentação de emendas ao orçamento proposto pelo Executivo e o controle das finanças públicas, a partir da nomeação dos membros do Tribunal de Contas da União pelo Congresso Nacional 2,3,4.

As mudanças refletem o momento da redemocratização e traduzem um esforço de ampliação da participação política no processo decisório, bem como a busca por um maior balanceamento entre os Poderes. Porém, os anos que seguiram a Constituição Federal de 1988 revelam os desafios da implementação dessas propostas, em especial no que tange ao processo orçamentário.

No que diz respeito aos instrumentos preconizados (PPA, LDO e LOA), persiste uma lógica institucional fragmentada, que se reproduz no âmbito dos programas definidos no PPA e na forma de distribuição dos recursos 1,5. No pro- 
cesso de elaboração orçamentária, mantém-se a supremacia do Poder Executivo, com a prerrogativa desse Poder de propor e decidir sobre a execução do gasto orçamentário aprovado 1,6. Já a emenda parlamentar, como mecanismo para maior participação política, mostrou-se permeável aos interesses e às práticas clientelistas do Estado, com sucessivos escândalos, na década de 1990, envolvendo o uso irregular de recursos públicos 7 .

Ainda assim, deve-se reconhecer que, desde a Constituição Federal de 1988, o Congresso Nacional tem buscado ajustar-se aos novos papéis que lhe foram deferidos, editando resoluções normativas (1991, 1995, 2001, 2003 e 2006) 8,9,10,11,12 com o objetivo de definir regras e limites para a apresentação das emendas parlamentares, particularmente as individuais, para o funcionamento da Comissão Mista de Orçamento e para a apreciação do orçamento propriamente dito 13 .

O volume das emendas parlamentares no orçamento público federal não é significativo em termos orçamentários, mantendo-se em torno de $2 \%$ do orçamento global 14 . Entretanto, destacam-se como parcela importante dos recursos de capital, que representam $10 \%$ do orçamento 5 .

Além dos montantes financeiros que as emendas mobilizam, alguns autores ressaltam seu importante papel como recurso político 15,16. As emendas parlamentares asseguram a "sobrevivência política” da maioria dos congressistas e também atuam como "moeda de troca" do Executivo Federal na relação entre os Poderes (Executivo e Legislativo) e entre as instâncias governamentais (nacional e subnacionais) à medida que são liberadas na garantia de votos favoráveis a projetos apresentados pela União.

Esse uso da emenda é reforçado pela regra que define que o orçamento é uma peça indicativa de gasto de caráter "autorizativo", mas não "impositivo" 1,6. Assim, o Poder Executivo é quem define a liberação de recursos orçamentários, não tendo que cumprir obrigatoriamente todas as ações e os recursos previstos e aprovados pelo Congresso. No caso das emendas, dado o jogo político que lhe é inerente, tal regra acaba por favorecer o uso dos recursos públicos como um instrumento de patronagem do Presidente da República na relação com o Congresso Nacional 16,17. Porém, para Souza 18, as regras estabelecidas também garantem uma "autonomia relativa" do Executivo na condução das políticas públicas, amenizando a prática de captação de recursos do Legislativo para atender demandas fisiológicas, que estariam voltadas mais para as vantagens políticas do que para o interesse público.

Estudos indicam que a prática dos parlamentares no Brasil remonta a um padrão políti- co de patronagem e fisiologismo na distribuição dos recursos com tendência de atuação em favor próprio 15,16, o que sugere a necessidade de maior regulação da distribuição de emendas por parte do Congresso. Nesse contexto, a adoção de um modelo de orçamento autorizativo, no qual a decisão do gasto se mantém no Executivo, também merece ser questionada, já que impõe uma nova negociação entre os Poderes para a aplicação dos recursos já definidos e aprovados e não amadurece a prática responsável do Executivo e do Legislativo, criando também dificuldades para o controle orçamentário pela população.

Portanto, o projeto original de fortalecimento do Legislativo previsto na Constituição, calcado na busca de maior equilíbrio entre Poderes de Estado como elemento central da democracia, esbarra nas características e lógica de funcionamento do próprio sistema político brasileiro 19 . As pesquisas também convergem em mostrar que as emendas parlamentares constituem um importante mecanismo para a participação do Legislativo no processo orçamentário e reiteram o argumento de limites na relação entre Poderes no Brasil, no que concerne à construção de políticas públicas mais equânimes e democráticas 14,15,16,18.

A saúde tem sido uma área importante no que tange à apresentação de emendas pelos parlamentares. No PPA 2004-2007, o número de emendas destinadas à saúde foi superior aos demais setores da política pública, mobilizando, em alguns anos, mais de $20 \%$ do recurso total das emendas (como em 2007) 13. O Ministério da Saúde é a segunda maior rubrica do orçamento federal por órgãos do governo, sendo precedido apenas pelo Ministério da Previdência Social 20, reunindo, portanto, um volume expressivo de recursos, estando mais sujeito à apresentação de emendas pelos parlamentares.

Esse setor também se diferencia pelas ações previstas em sua programação, que se caracterizam por ser de execução objetiva e de grande visibilidade (como aquisição de equipamentos, veículos, medicamentos, pequenas obras e instalações, entre outras), sendo mais fácil destinálas a localidades, unidades de saúde ou projetos específicos, tanto no âmbito público como no privado, indo ao encontro dos interesses dos parlamentares.

Talvez, por esses motivos, as denúncias de uso irregular ou ilícito de recursos de emendas estejam, muitas vezes, associadas à área da saúde, como em 1993, na Comissão Parlamentar Mista de Inquérito que investigou irregularidades no processo orçamentário (CPMI do Orçamento) 21; ou em 2006, na Comissão Parlamentar de Inquérito (CPI) que investigou a compra de 
ambulâncias e insumos estratégicos (CPMI das Ambulâncias) 22.

De fato, o destino da emenda é um ponto frágil do modelo orçamentário, o que se agrava num cenário de pouca transparência e de ausência de controle mais efetivo sobre os recursos, seja na apresentação e aprovação do orçamento, seja no momento de sua execução.

Aprofundar estudos sobre a definição e o uso das emendas parlamentares no âmbito da saúde pode ajudar a esclarecer e tornar, mais transparentes, os desafios que se apresentam nesse âmbito da política.

Este artigo visa contribuir para esse debate ao analisar a participação das emendas parlamentares no orçamento federal da saúde no período de 1997-2006, buscando identificar o peso das emendas da saúde no orçamento e explorar algumas hipóteses explicativas que permeiam o processo político e decisório na distribuição desses recursos entre regiões e estados brasileiros.

O texto segue com uma descrição da metodologia adotada no desenvolvimento do estudo e apresenta os resultados obtidos na análise das emendas parlamentares da saúde no período em questão. Finaliza-se com uma discussão acerca dos mecanismos institucionais utilizados na definição, distribuição e controle das emendas parlamentares da saúde e suas repercussões para o financiamento e planejamento do SUS.

\section{Metodologia}

A análise da participação das emendas parlamentares no orçamento federal da saúde no período de 1997-2006 foi feita a partir dos dados de execução orçamentária regionalizada do Ministério da Saúde. Esses dados correspondem aos recursos empenhados a cada ano e não expressam, portanto, toda a despesa liquidada e paga pelo Ministério, visto que existe a possibilidade de cancelamento ou suspensão de compromissos financeiros da União no processo orçamentário.

Além disso, os dados dizem respeito somente aos recursos cuja destinação regional pode ser identificada. Dessa forma, não estão incluídas as despesas que não são passíveis de apropriação regional, como os gastos com inativos, pagamentos de dívidas, pessoal ativo da União ou despesas com a gestão central de políticas e programas federais.

A base assim constituída possibilitou a análise da evolução da execução de emendas no período, em valores corrigidos pela inflação aferida pelo Índice Nacional de Preços ao Consumidor Amplo (IPCA) do Instituto Brasileiro de Geografia e Estatística (IBGE); a identificação do percentual de emendas executadas; o peso das emendas no orçamento do Ministério da Saúde, por natureza da despesa (custeio e investimento) e por finalidade de investimento (infraestrutura do SUS ou saneamento); e a distribuição das emendas por regiões e estados, numa série histórica de 10 anos da execução regionalizada.

A base não contém informações relativas às ações previstas e à autoria da emenda (parlamentar e partido no caso das emendas individuais, bancadas ou comissões no caso das emendas coletivas), o que possibilitaria uma compreensão mais precisa sobre a natureza das emendas e como elas poderiam ou não compensar desigualdades nas diferentes localidades. Atente-se que as informações sobre o orçamento público federal são de domínio público desde a Constituição Federal de 1988, com a divulgação, em Diário Oficial, das leis aprovadas e da execução orçamentária. Os orçamentos anuais estão disponíveis na página do Senado Federal, desde o ano 2000, por meio do Sistema SIGA 20, que apresenta as informações por órgão, função, programa, área, autoria, unidade orçamentária, natureza da despesa, valores apresentados, aprovados e todo o processo de empenho e pagamento das ações previstas, além de outras variáveis. Contudo, as informações disponíveis, a partir do valor aprovado, estão agregadas por grandes programas e ações, não possibilitando, por exemplo, a identificação do valor empenhado e pago por autor ou por emenda. Esse é um problema para o entendimento sobre a execução orçamentária, visto que o orçamento tem caráter indicativo, mas nem sempre é completamente executado.

A informação sobre a execução orçamentária no nível de detalhamento necessário para o acompanhamento das ações aprovadas ainda está restrita ao Poder Executivo. Desde 2009, o Ministério da Saúde disponibiliza as informações de emendas por autoria na sala de situação de sua página virtual. Contudo, o acesso apenas possibilita a visualização dos dados por parlamentar em cada estado, o que dificulta a consolidação de uma base única para estados e regiões e a comparação de dados.

Este estudo representa uma primeira tentativa de explorar e analisar as características gerais da execução orçamentária das emendas parlamentares da saúde, sendo ainda necessário consolidar informações relativas às ações e às autorias na execução, que, no momento, são de acesso restrito. A pesquisa foi aprovada pelo Comitê de Ética da organização acadêmica responsável pelo estudo e obteve o consentimento livre e esclarecido do Ministro da Saúde para a obtenção dos dados. 


\section{Resultados}

O período de 1997-2006 abrange a execução de três diferentes PPA - 1996/1999, 2000/2003, 2004/2007 - o que corresponde aos dois primeiros mandatos do governo de Fernando Henrique Cardoso (FHC) e ao primeiro mandato do governo de Luiz Inácio Lula da Silva (Lula). Esses períodos correspondem também a três diferentes legislaturas, com variações no perfil dos parlamentares e na base governista (federal e estadual), o que influencia a definição das emendas, bem como a sua execução nos estados e regiões. Cada um dos PPA também se insere em momentos diferentes da política de saúde e do financiamento do SUS, sendo necessário compreender a participação das emendas em cada macro contexto da política.

No período analisado, a execução orçamentária regionalizada representou entre $51,1 \%$ e $68 \%$ da execução orçamentária total do Ministério da Saúde e entre $61,1 \%$ e $79,0 \%$ da execução orçamentária do Ministério com ações e serviços de saúde (que exclui pagamento de inativos, dí- vida e fundo de combate à pobreza/programas de transferência de renda). O orçamento regionalizado da saúde no período de 1997-2006, em valores ajustados pela inflação, apresentou um acréscimo gradativo de recursos a cada ano, especialmente a partir de 1999 (Figura 1). Tal acréscimo condiz com a trajetória de financiamento do período, visto que, apenas a partir de 1999, inicia-se um período de maior estabilidade no orçamento 23 .

O ano de 2003 é atípico nessa série e reflete, pelo menos, dois movimentos: de um lado, o momento de transição entre os governos FHC e Lula, com o último ano de orçamento aprovado pelo governo FHC; de outro, o momento de crise econômica mundial, no ano de 2002, determinando a manutenção de políticas de controle e estabilização da moeda 24 . O período de 2004-2006 foi o de maior crescimento na série, alcançando, no último ano, 46 bilhões de reais. Ressalte-se que ocorreram mudanças importantes na peça orçamentária da saúde no primeiro PPA do governo Lula. O Ministério da Saúde incorporou, provisoriamente, em sua rubrica, o Programa de

Figura 1

Valores executados do orçamento total, do orçamento regionalizado, dos investimentos em saúde e total de emendas (em R\$ de dezembro de 2007). Brasil, 1997-2006.

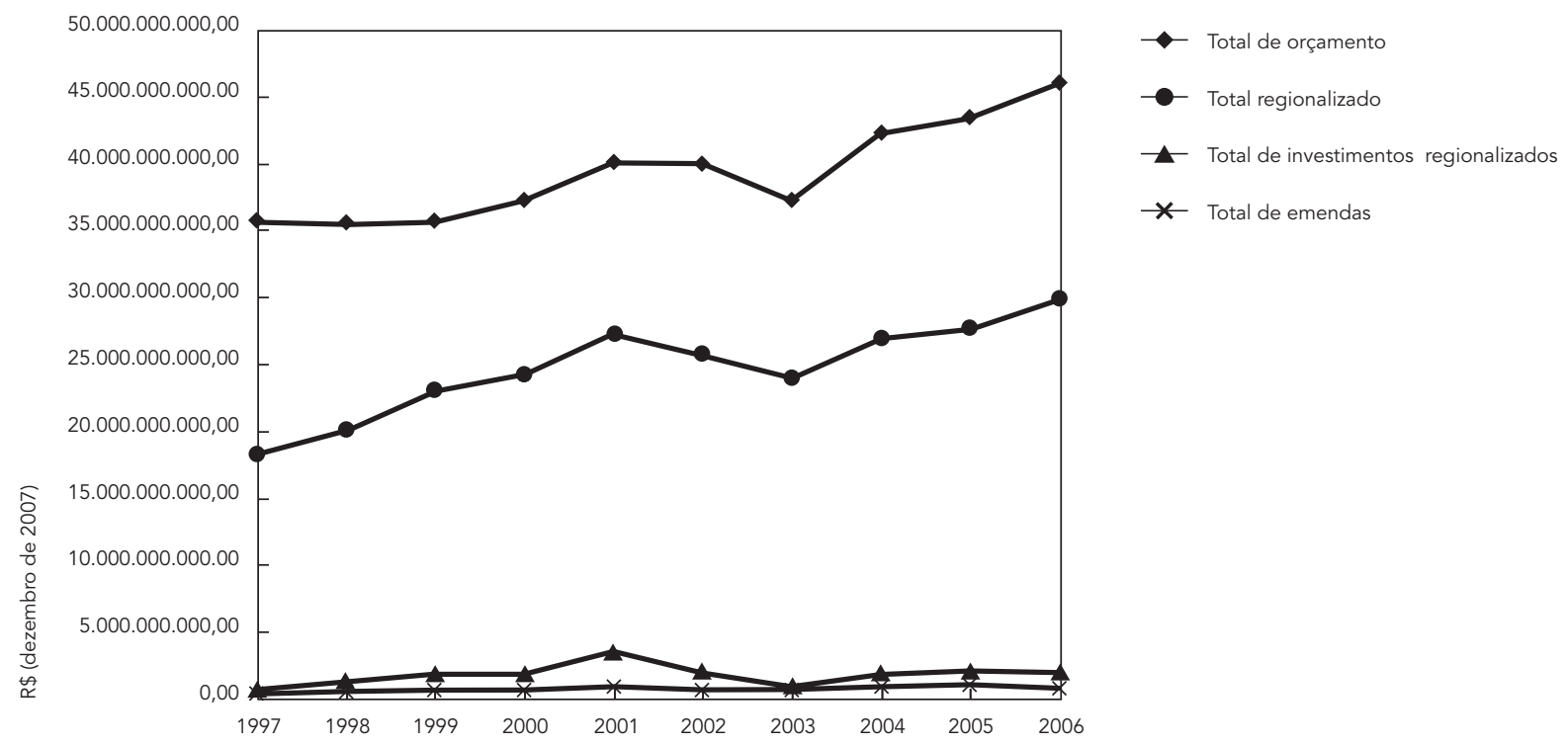

Fonte: Subsecretaria de Planejamento e Orçamento, Secretaria Executiva, Ministério da Saúde. Planilhas da execução orçamentária regionalizada. Nota: Os valores foram ajustados para R\$ de dezembro de 2007, considerando o Índice de Preços ao Consumidor Amplo (IPCA) do Instituto Brasileiro de Geografia e Estatística. 
Transferência de Renda com Condicionalidades (Bolsa Família) e o Programa de Saneamento Ambiental Urbano, esse presente, até então, na programação do Ministério das Cidades. No caso do saneamento, cabe indicar a adequação dessas ações aos perfis das emendas.

Observou-se baixa participação dos investimentos no orçamento regionalizado, com pequenas variações nos anos (Figura 1), obtendo o maior patamar no ano de 2001 (12,8\% dos recursos regionalizados). O ano de 2001 é atípico na série, o que pode ser explicado pela execução do Projeto Alvorada, no final do governo FHC. Tal projeto abrangia recursos de investimentos em construção, reforma e ampliação de unidades, aquisição de equipamentos, entre outros, em várias áreas, com o propósito de reduzir as desigualdades regionais por meio da melhoria das condições de vida da população dos estados que apresentavam Índice de Desenvolvimento Humano inferior a 0,5 25.

Os recursos de investimento, em geral, giraram em torno de $4,5 \%$ no orçamento global e $6,5 \%$ no orçamento regionalizado. Os anos de menor montante de recursos foram 1997, 1998 e 2003, que representaram momentos críticos para o financiamento da saúde, com oscilações importantes nos gastos federais. A queda sugere que os investimentos programados tenham sido objeto de cortes orçamentários e indica a fragilidade financeira dos projetos de investimento formulados e conduzidos nacionalmente.

Machado 26, em estudo sobre a condução da política do Ministério da Saúde de 1990-2002, ressalta a ausência de um planejamento nacional de investimentos em saúde de médio e longo prazo, não observando critérios voltados para a promoção da equidade que orientassem a implementação de ações a partir de uma base de financiamento estável durante esse período. Aponta também para as limitações do Governo Federal e do Ministério da Saúde, em particular, no desempenho do que seria uma de suas atribuições mais relevantes: a realização de investimentos com o objetivo de reduzir as desigualdades na oferta de ações e serviços de saúde no território nacional, sendo essa uma questão crucial no desenvolvimento do SUS.

No contexto dos investimentos, inserem-se as emendas parlamentares. Observa-se, na Figura 1, que as emendas têm um peso inexpressivo no orçamento regionalizado, não ultrapassando, em ano algum, percentual superior a 3,7\% do orçamento. Já na comparação das emendas com os recursos de investimento, pode-se observar que essas se aproximam, em quase toda a série, do montante de investimentos regionalizados, com exceção do ano de 2001. Na série históri- ca, as emendas totais variaram de $25,1 \%$ a $58,6 \%$ dos investimentos regionalizados, apresentando os maiores percentuais a partir de 2003 (Figura 2). Assim, em que pese a relativa escassez de recursos de investimento no orçamento global e regionalizado, as emendas representam mais da metade desses recursos em alguns anos e têm ocupado um lugar importante na negociação intergovernamental e parlamentar para a obtenção de novas fontes de receita de capital.

Na Figura 2, observa-se que as emendas da saúde são majoritariamente de investimento, predominando as emendas de infraestrutura no período analisado. Para uma análise mais precisa da distribuição das emendas de investimento por finalidade (infraestrutura e saneamento), seria importante identificar o destino e as ações propostas, cruzando tais informações com os períodos de execução de cada PPA e as coalizões político-partidárias estabelecidas.

A partir do ano 2000, verifica-se um pequeno percentual de emendas de custeio que raramente ultrapassaram $10 \%$ do total de emendas (1998, 2002 e 2003). É curioso que existam emendas de custeio, tendo em vista que essas ações deveriam constar no orçamento proposto pelo Executivo, dada a sua necessária continuidade. Porém, sua apresentação se justifica na negociação entre parlamentares, Executivo - federal, estadual e municipal - e prestadores de serviço - públicos e privados - que envolve o processo de elaboração orçamentária, com o objetivo de garantir a manutenção de áreas, serviços e ações em curso. Um exemplo de emendas de custeio na saúde são aquelas destinadas à Associação das Pioneiras Sociais (instituição gestora da Rede SARAH de Hospitais de Reabilitação), que recebem anualmente recursos de emendas de um número expressivo de parlamentares, cuja explicação exige a realização de investigação específica.

A análise da participação percentual das emendas no orçamento segundo regiões é um primeiro passo na identificação das formas de distribuição e localização dos recursos. A Tabela 1 mostra que não existe um padrão regular de distribuição regional das emendas em todo o período, o que é coerente com a natureza desse recurso. Entretanto, utilizando-se, como referência, os períodos de vigência de cada PPA (1996/1999; 2000/2003; 2004/2007), é possível identificar alguns destinos mais recorrentes.

A Região Norte, por exemplo, obteve, no período do PPA 1996/1999, um volume constante e expressivo de recursos em relação às demais regiões, apresentou o maior percentual de emendas em relação ao orçamento regionalizado e também os maiores valores per capita (Tabela 2). É importante também destacar o peso das 
Figura 2

Emendas parlamentares por natureza da despesa (custeio e investimentos), por finalidade do investimento (infraestrutura e saneamento) e como percentual das emendas de investimento no investimento regionalizado (em valores \%). Brasil, 1997-2006.

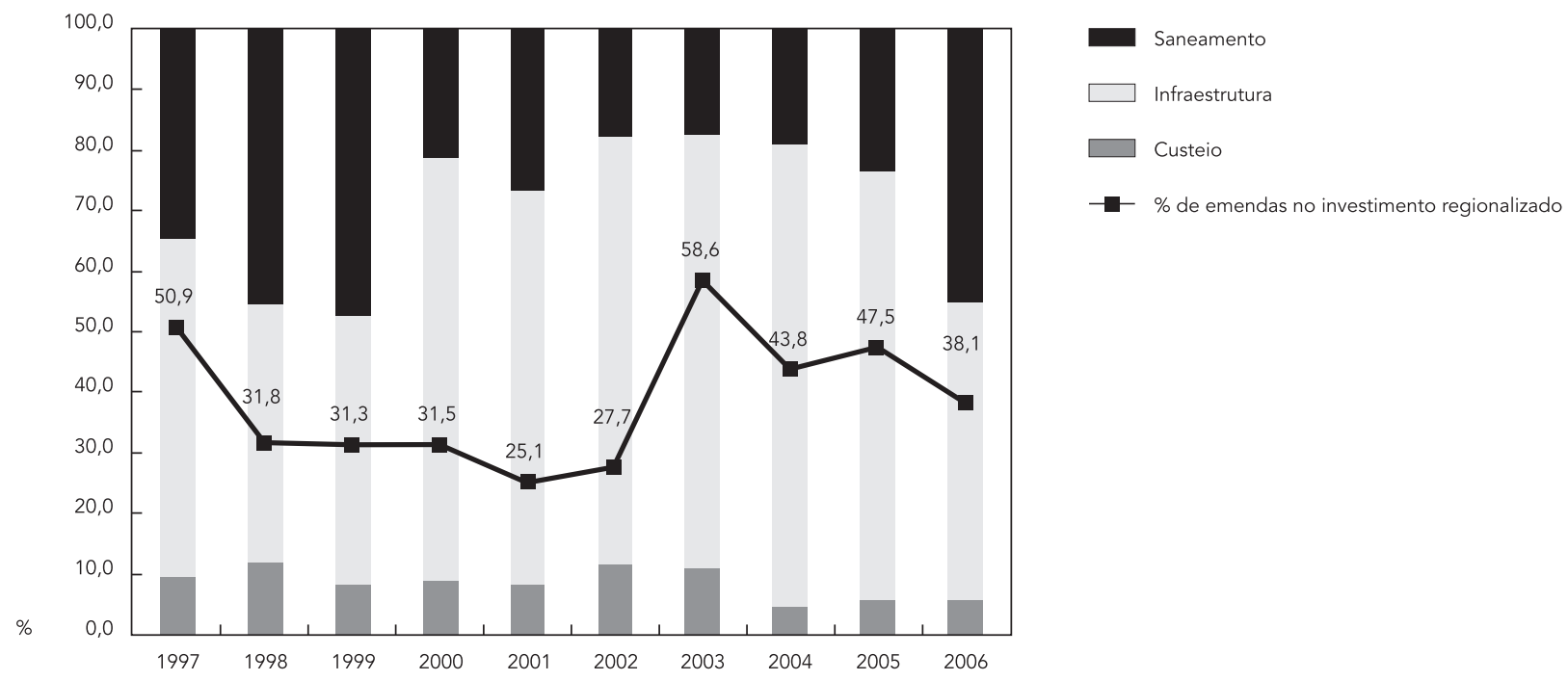

Fonte: Subsecretaria de Planejamento e Orçamento, Secretaria Executiva, Ministério da Saúde. Planilhas da execução orçamentária regionalizada.

emendas no total de recursos de investimento obtido pela região nesses três anos, indicando uma alta dependência das emendas para a obtenção de recursos de capital. No período correspondente ao PPA seguinte, observa-se uma diminuição brusca dessa participação, especialmente no primeiro ano, aproximando-se do comportamento das demais regiões, mas, ainda assim, mantendo-se acima da média nacional (Brasil). A região apresenta um novo acréscimo percentual das emendas no período do PPA 2004/2007, que se mantém constante até o final da série.

A Região Nordeste apresentou comportamento estável em toda a série, com ligeira queda no PPA 2000/2003 e aumento mais significativo no último PPA, tornando-se mais próxima da Região Norte. O inverso ocorreu com a Região Centro-Oeste, com aumento no PPA 2000/2003 e declínio no seguinte.

Já as regiões Sul e Sudeste apresentaram percentuais de participação muito próximos, com oscilações pequenas e constantes, mobilizando percentuais de recursos entre $1,1 \%$ a $3,4 \%$, não havendo variação em função dos PPA, embora com uma tendência de crescimento entre 20002003. Destaca-se também o percentual de emendas no total de recursos de investimento nessas duas regiões.
Por fim, verifica-se que, desde 2003, há uma aproximação entre as regiões no que tange à participação das emendas no orçamento regionalizado, com exceção da Região Centro-Oeste. Chama a atenção ainda o peso das emendas nos investimentos federais em todos os anos, mas especialmente nos anos de 1997 e 2003, momentos desfavoráveis para o financiamento federal da saúde (Tabela 1).

Esses dados ganham ainda mais sentido quando é feita a comparação dos valores de emendas por região em relação à execução dos recursos destinados à atenção básica.

Comparando-se o montante de recursos de emendas com os principais incentivos de atenção básica (o Piso de Atenção Básica - PAB fixo, o Programa Agentes Comunitários de Saúde - PACS/PSF e o incentivo da farmácia básica), chama atenção o peso das emendas na Região Norte, que representaram, em alguns anos, mais de $30 \%$ do montante dos recursos destinados à atenção básica, como nos anos de 1997, 1998, 1999 e 2001. Também na Região Centro-Oeste, entre 1999 e 2001, e na Região Sudeste, em 2001 e 2005, as emendas representaram mais de $20 \%$ dos recursos destinados aos referidos incentivos da atenção básica somados (Tabela 2).

No entanto, esse dado é influenciado pela adesão dos municípios dos vários estados às 
Tabela 1

Participação proporcional (\%) das emendas no orçamento regionalizado e nos investimentos do Ministério da Saúde por regiões. Brasil, $1997-2006$.

\begin{tabular}{|c|c|c|c|c|c|c|c|c|c|c|}
\hline Regiões & 1997 & 1998 & 1999 & 2000 & 2001 & 2002 & 2003 & 2004 & 2005 & 2006 \\
\hline \multicolumn{11}{|c|}{ Emendas no orçamento regionalizado do } \\
\hline \multicolumn{11}{|c|}{ Ministério da Saúde (\%) } \\
\hline Norte & 8,5 & 8,0 & 9,4 & 3,6 & 5,8 & 4,3 & 4,9 & 6,2 & 5,8 & 4,9 \\
\hline Nordeste & 2,6 & 2,6 & 2,9 & 2,5 & 2,4 & 2,5 & 3,1 & 4,0 & 3,7 & 3,7 \\
\hline Centro-Oeste & 3,0 & 2,2 & 3,4 & 4,2 & 4,2 & 3,1 & 2,5 & 3,0 & 3,3 & 2,6 \\
\hline Sudeste & 1,1 & 1,6 & 1,7 & 2,3 & 3,3 & 2,2 & 1,9 & 2,5 & 3,4 & 1,5 \\
\hline Sul & 2,0 & 1,7 & 1,8 & 2,7 & 2,9 & 1,9 & 1,9 & 2,4 & 2,7 & 1,6 \\
\hline Brasil & 2,1 & 2,3 & 2,7 & 2,6 & 3,5 & 2,4 & 2,6 & 3,2 & 3,7 & 2,7 \\
\hline \multirow{2}{*}{\multicolumn{11}{|c|}{$\begin{array}{l}\text { Emendas investimento/total de investimentos } \\
\text { regionalizados (\%) }\end{array}$}} \\
\hline & & & & & & & & & & \\
\hline Norte & 61,5 & 52,6 & 45,4 & 25,0 & 19,3 & 25,0 & 60,8 & 45,3 & 48,5 & 40,3 \\
\hline Nordeste & 45,9 & 32,5 & 30,5 & 38,1 & 11,6 & 20,7 & 67,4 & 44,2 & 42,1 & 41,9 \\
\hline Centro-Oeste & 46,8 & 23,5 & 29,3 & 43,2 & 49,6 & 23,5 & 44,7 & 24,5 & 29,9 & 20,7 \\
\hline Sudeste & 46,1 & 26,0 & 24,2 & 43,6 & 47,7 & 41,1 & 61,1 & 50,3 & 55,1 & 32,0 \\
\hline Sul & 69,4 & 31,4 & 34,9 & 53,8 & 54,9 & 41,7 & 62,6 & 39,2 & 43,0 & 38,9 \\
\hline Brasil & 50,9 & 31,8 & 31,3 & 31,5 & 25,1 & 27,7 & 58,6 & 43,8 & 47,5 & 38,1 \\
\hline
\end{tabular}

Fonte: Subsecretaria de Planejamento e Orçamento, Secretaria Executiva, Ministério da Saúde. Planilhas da execução orçamentária regionalizada.

Tabela 2

Relação entre valores executados das emendas e dos incentivos federais para a atenção básica no orçamento do Ministério da Saúde (em valores \%). Brasil e regiões, 1997-2006

\begin{tabular}{|c|c|c|c|c|c|c|c|c|c|c|}
\hline Regiões & 1997 & 1998 & 1999 & 2000 & 2001 & 2002 & 2003 & 2004 & 2005 & 2006 \\
\hline \multicolumn{11}{|c|}{ Relação emendas/principais incentivos da atenção } \\
\hline \multicolumn{11}{|c|}{ básica (PAB fixo, PACS/PSF e farmácia básica) [\%] } \\
\hline Norte & 42,4 & 36,3 & 50,3 & 17,7 & 34,1 & 19,4 & 20,9 & 27,8 & 23,8 & 19,5 \\
\hline Nordeste & 12,7 & 11,2 & 13,3 & 10,9 & 12,1 & 10,5 & 12,6 & 15,5 & 13,5 & 12,7 \\
\hline Centro-Oeste & 18,8 & 12,7 & 20,7 & 23,4 & 21,7 & 16,2 & 12,9 & 15,8 & 15,6 & 13,0 \\
\hline Sudeste & 7,3 & 9,8 & 11,5 & 16,0 & 23,5 & 14,2 & 12,7 & 16,7 & 21,6 & 9,1 \\
\hline Sul & 14,0 & 10,9 & 11,7 & 16,4 & 17,3 & 10,6 & 10,1 & 13,2 & 13,8 & 7,7 \\
\hline Brasil & 13,0 & 12,4 & 15,8 & 15,0 & 21,2 & 13,1 & 13,8 & 16,9 & 18,2 & 12,5 \\
\hline \multicolumn{11}{|c|}{ Relação emendas/PAB fixo [\%] } \\
\hline Norte & 49,9 & 44,7 & 72,0 & 29,5 & 63,4 & 37,7 & 43,5 & 61,2 & 56,0 & 49,0 \\
\hline Nordeste & 15,1 & 14,0 & 18,5 & 18,5 & 23,4 & 22,4 & 30,0 & 41,9 & 38,9 & 40,9 \\
\hline Centro-Oeste & 21,0 & 14,8 & 26,9 & 37,4 & 39,6 & 29,7 & 26,9 & 34,9 & 36,8 & 30,6 \\
\hline Sudeste & 7,8 & 10,8 & 13,2 & 20,6 & 32,6 & 22,0 & 20,5 & 28,9 & 38,4 & 17,5 \\
\hline Sul & 15,0 & 12,2 & 13,9 & 23,2 & 26,6 & 18,4 & 20,0 & 27,1 & 29,8 & 18,0 \\
\hline Brasil & 14,5 & 14,3 & 19,7 & 22,2 & 34,7 & 23,6 & 26,9 & 36,0 & 40,6 & 30,4 \\
\hline
\end{tabular}

PAB: Piso de Atenção Básica; PACS: Programa Agentes Comunitários de Saúde; PSF: Programa Saúde de Família.

Fonte: Subsecretaria de Planejamento e Orçamento, Secretaria Executiva, Ministério da Saúde. Planilhas da execução orçamentária regionalizada. 
estratégias de Agentes Comunitários de Saúde (ACS) e, principalmente, de Saúde da Família. Isso porque o financiamento do Programa Saúde da Família (PSF), política prioritária para o Ministério da Saúde, baseia-se no número de equipes implantadas e na cobertura populacional alcançada nos municípios. Para ilustrar a importância relativa das emendas evitando esse efeito da adesão a uma estratégia específica, comparou-se o montante destinado às emendas com o correspondente ao PAB fixo, que segue critério de distribuição populacional, com maior flexibilidade de aplicação pelos governos municipais.

Assim, comparando-se o peso das emendas em relação ao PAB fixo (Tabela 2), verificou-se que, na Região Norte, na maior parte dos anos, a execução de recursos de emendas superou $40 \%$ dos recursos do PAB fixo, chegando a ultrapassar $60 \%$ nos anos de 2001 e 2004 e $70 \%$ em 1999. Nas demais regiões, o peso relativo das emendas também se mostrou significativo em comparação ao PAB fixo, com uma tendência de aumento entre 2003 e 2006, principalmente na Região Nordeste.

Esses dados indicam que o volume de recursos das emendas supera, em algumas regiões, os recursos/incentivos de programas oficiais e estratégicos do Ministério da Saúde, sugerindo uma inversão na lógica de planejamento e organização do sistema de saúde.

Já para uma análise mais precisa acerca do processo político que permeia a distribuição regional das emendas, seria importante considerar a base política do governo tanto no Executivo (estadual e municipal) como no Congresso Nacional por Unidade da Federação (UF). O Ministério da Saúde e a Casa Civil acompanham a execução das emendas segundo sua autoria, o que possibilita estabelecer uma relação entre ação proposta e sua base de apoio. Essas informações não foram analisadas no âmbito deste estudo, mas, com os dados apresentados, é possível indicar quais regiões e estados foram favorecidos pela liberação de suas emendas em diferentes períodos e qual a importância desse instrumento para a obtenção de recursos de investimento pelas regiões.

A análise da execução orçamentária por UF (Tabela 3) permite identificar os estados que se destacaram pelo volume de recursos per capita de emendas em cada região: (1) Norte: Acre, Amapá e Roraima, nos três períodos, em especial 1997/ 1999 para Acre e Roraima; (2) Nordeste: Alagoas, Ceará e Rio Grande do Norte no primeiro período; Alagoas, Rio Grande do Norte e Paraíba no terceiro período; (3) Centro-Oeste: Mato Grosso do Sul no primeiro e Mato Grosso no segundo e terceiro períodos; (4) Sudeste: Espírito Santo e Minas Gerais de 2000-2003 e Espírito Santo e
Rio de Janeiro de 2004-2006; e (5) Sul: Paraná em todos os anos, acima da média da região.

Todos esses estados tiveram variações na série, mas também mantiveram uma participação constante e acima dos demais estados no recebimento desses recursos, especialmente no recorte por PPA. Em alguns estados, os recursos das emendas corresponderam a mais de $70 \%$ dos investimentos, como no Acre, Amapá, Roraima, Bahia, Ceará, Espírito Santo, Minas Gerais, Paraná e Rio Grande do Sul. Nos demais estados, as oscilações foram recorrentes.

\section{Discussão}

Após a promulgação da Constituição Brasileira de 1988, que introduziu novas regras referentes ao equilíbrio de Poderes de Estado, houve, na área da Ciência Política, uma expressiva produção voltada para as mudanças nas relações entre Executivo e Legislativo, dada a sua importância para as políticas públicas em um contexto democrático 2,3,4,27. É nesse contexto que se inserem os estudos sobre a participação do Legislativo no processo orçamentário nacional e, mais especificamente, sobre as emendas parlamentares ao orçamento 5,7,14,15,16,28.

Apesar da importância das emendas da saúde no total das emendas parlamentares, pesquisas específicas com enfoque setorial ainda são raras 13. Ademais, a análise das emendas é relevante para a compreensão da lógica e dos limites no planejamento e na execução do orçamento da saúde, influenciado não somente por regras mais gerais do sistema político e da execução orçamentária federal, como também por especificidades de cada área.

Sem pretender esgotar o tema, esse artigo analisou a execução das emendas parlamentares no orçamento federal da saúde em um período de dez anos (1997-2006), buscando explorar a sua relevância orçamentária e distribuição territorial. Foi possível ainda identificar limites nas bases de dados disponíveis e levantar hipóteses relativas às relações entre Poderes e entre planejamento e orçamentação em saúde a serem aprofundadas em estudos posteriores.

Os dados apresentados revelam que, embora as emendas não tenham um peso muito importante na execução do orçamento regionalizado do Ministério da Saúde, elas representam uma proporção expressiva dos investimentos federais em saúde. Tal característica se torna ainda mais evidente em anos de restrições orçamentárias, em que as emendas assumem maior importância para a distribuição e a captação desses recursos. 
Tabela 3

Execução das emendas no orçamento do Ministério da Saúde segundo regiões e estados, valores per capita (em $\mathrm{R} \$$ de dezembro de 2007). Brasil, 1997-2006.

\begin{tabular}{|c|c|c|c|c|c|c|c|c|c|c|}
\hline Regiões/Estados & 1997 & 1998 & 1999 & 2000 & 2001 & 2002 & 2003 & 2004 & 2005 & 2006 \\
\hline Norte & 7,2 & 7,5 & 11,6 & 4,5 & 9,6 & 5,4 & 5,5 & 7,8 & 7,5 & 7,0 \\
\hline$A C$ & 54,4 & 50,1 & 86,8 & 6,7 & 30,4 & 10,3 & 18,8 & 28,0 & 24,6 & 32,4 \\
\hline$A P$ & 9,6 & 10,8 & 30,4 & 40,1 & 27,2 & 12,8 & 14,0 & 26,4 & 22,6 & 13,4 \\
\hline AM & 1,9 & 0,4 & 6,7 & 2,0 & 9,3 & 7,5 & 4,6 & 5,1 & 7,9 & 6,0 \\
\hline PA & 1,9 & 3,0 & 3,3 & 1,4 & 3,2 & 2,9 & 1,9 & 4,4 & 4,5 & 2,7 \\
\hline $\mathrm{RO}$ & 11,1 & 3,8 & 5,5 & 6,0 & 20,4 & 9,0 & 12,7 & 8,2 & 8,1 & 7,6 \\
\hline $\mathrm{RR}$ & 58,9 & 53,9 & 101,7 & 1,6 & 50,7 & 10,8 & 29,4 & 26,8 & 8,9 & 35,6 \\
\hline TO & 8,2 & 19,2 & 9,6 & 11,0 & 2,3 & 2,1 & 1,9 & 8,7 & 5,2 & 7,3 \\
\hline Nordeste & 2,6 & 2,8 & 3,6 & 3,2 & 3,8 & 3,5 & 3,9 & 5,7 & 5,4 & 5,9 \\
\hline $\mathrm{AL}$ & 7,7 & 7,9 & 7,5 & 5,3 & 0,5 & 2,0 & 2,1 & 4,8 & 6,0 & 7,4 \\
\hline BA & 0,7 & 1,3 & 1,0 & 0,7 & 2,1 & 2,7 & 3,1 & 4,1 & 3,2 & 2,9 \\
\hline CE & 4,6 & 2,4 & 5,3 & 1,4 & 6,4 & 3,7 & 5,6 & 4,7 & 6,0 & 7,7 \\
\hline MA & 1,5 & 1,3 & 1,8 & 3,4 & 4,1 & 2,5 & 3,5 & 4,2 & 6,4 & 6,7 \\
\hline PB & 2,5 & 5,5 & 4,8 & 4,1 & 2,1 & 8,7 & 2,3 & 9,4 & 13,0 & 14,2 \\
\hline PE & 2,5 & 3,0 & 3,2 & 3,4 & 3,5 & 3,6 & 5,2 & 5,7 & 4,7 & 3,9 \\
\hline $\mathrm{PI}$ & 3,7 & 0,7 & 1,8 & 5,4 & 4,0 & 2,9 & 3,8 & 8,0 & 0,7 & 10,4 \\
\hline RN & 3,8 & 1,4 & 14,2 & 9,2 & 11,3 & 4,1 & 4,6 & 10,2 & 7,9 & 4,9 \\
\hline $\mathrm{SE}$ & 1,4 & 12,8 & 2,3 & 8,0 & 3,4 & 2,6 & 4,3 & 9,9 & 6,8 & 1,9 \\
\hline Centro-Oeste & 3,5 & 2,9 & 5,1 & 6,2 & 6,6 & 5,0 & 3,5 & 4,6 & 4,9 & 4,3 \\
\hline DF & 0,0 & 0,0 & 10,2 & 8,0 & 2,6 & 2,5 & 1,1 & 3,5 & 2,2 & 0,3 \\
\hline GO & 1,6 & 1,0 & 2,1 & 2,4 & 3,7 & 4,4 & 2,7 & 4,4 & 3,9 & 3,1 \\
\hline $\mathrm{MT}$ & 1,6 & 8,0 & 6,6 & 13,5 & 17,2 & 9,4 & 7,6 & 4,9 & 9,9 & 8,4 \\
\hline MS & 13,7 & 4,3 & 5,2 & 5,1 & 4,9 & 3,8 & 2,8 & 6,1 & 3,9 & 6,3 \\
\hline Sudeste & 1,3 & 2,2 & 2,6 & 3,3 & 5,0 & 3,2 & 2,7 & 3,9 & 5,2 & 2,4 \\
\hline ES & 2,0 & 12,3 & 4,1 & 5,2 & 20,9 & 3,6 & 5,9 & 7,4 & 4,2 & 4,5 \\
\hline RJ & 1,3 & 1,1 & 2,9 & 3,4 & 5,2 & 4,6 & 4,0 & 5,3 & 8,2 & 2,7 \\
\hline $\mathrm{SP}$ & 1,2 & 2,1 & 2,2 & 2,9 & 3,2 & 2,6 & 1,8 & 2,9 & 4,3 & 2,1 \\
\hline MG & 1,6 & 1,4 & 2,7 & 3,9 & 6,0 & 3,2 & 3,0 & 4,1 & 5,0 & 2,7 \\
\hline Sul & 2,3 & 2,2 & 2,5 & 4,0 & 4,3 & 2,7 & 2,7 & 3,8 & 4,1 & 2,5 \\
\hline PR & 3,5 & 2,5 & 3,6 & 4,3 & 4,7 & 3,5 & 2,6 & 4,0 & 4,3 & 2,6 \\
\hline $\mathrm{SC}$ & 1,2 & 1,0 & 1,1 & 4,5 & 3,9 & 2,4 & 2,7 & 3,6 & 3,1 & 2,9 \\
\hline RS & 1,8 & 2,6 & 2,1 & 3,6 & 4,1 & 2,2 & 2,7 & 3,6 & 4,4 & 2,3 \\
\hline Brasil & 2,4 & 2,8 & 3,7 & 3,7 & 5,5 & 3,6 & 3,5 & 4,8 & 5,5 & 4,3 \\
\hline
\end{tabular}

AC: Acre; AL: Alagoas; AM: Amazonas; AP: Amapá; BA: Bahia; CE: Ceará; DF: Distrito Federal; ES: Espírito Santo; GO: Goiás; MA: Maranhão; MG: Minas Gerais; MS: Mato Grosso do Sul; MT: Mato Grosso; PA: Pará; PB: Paraíba; PE: Pernambuco; PI: Piauí; PR: Paraná; RJ: Rio de Janeiro; RN: Rio Grande do Norte; RO: Rondônia; RR: Roraima; RS: Rio Grande do Sul; SC: Santa Catarina; SE: Sergipe; SP: São Paulo; TO: Tocantins.

Fonte: Subsecretaria de Planejamento e Orçamento, Secretaria Executiva, Ministério da Saúde. Planilhas da execução orçamentária regionalizada.

Nota: Os valores foram ajustados para R\$ de dezembro de 2007, considerando o Índice de Preços ao Consumidor Amplo (IPCA) do Instituto Brasileiro de Geografia e Estatística. 
Verificou-se que há uma expressiva variação dos indicadores entre as regiões e estados brasileiros, indicando que o dado nacional referente a um ano selecionado pode ocultar diferenças significativas de execução das emendas nas distintas realidades territoriais. Em que pese a maior importância relativa das emendas (nos orçamentos regionalizados e em valores per capita) nas regiões Norte, Nordeste e Centro-Oeste, há variações entre estados de uma mesma região em diversos anos analisados. Ou seja, mesmo o dado regional mascara diferenças intrarregionais expressivas. A existência de determinados perfis de execução orçamentária em períodos de vigência de um PPA sugere a influência de contextos políticos específicos (incluindo coalizões político-partidárias e bases de apoio locais) na distribuição regional das emendas da saúde. Contudo, não foi possível estabelecer relações mais precisas, indicando a necessidade de estudos futuros que aprofundem tal aspecto.

A comparação dos recursos das emendas com os incentivos federais da atenção básica permite identificar sua relevância como instrumento de financiamento da saúde. A atenção básica tem sido considerada uma área prioritária da política nacional de saúde pelo papel estratégico que ocupa na reconfiguração do sistema de saúde e do modelo de atenção 29 . Assim, é impressionante constatar que as emendas parlamentares, com seu padrão instável, representam, para alguns estados, mais de $50 \%$ dos valores destinados aos principais incentivos de atenção básica ou do valor correspondente ao $\mathrm{PAB}$ fixo.

$\mathrm{O}$ volume relativamente baixo dos investimentos federais totais em saúde, o peso das emendas parlamentares nos investimentos e as variações importantes na sua execução entre estados e anos analisados alertam para dois grupos de problemas. O primeiro grupo refere-se às limitações na articulação entre planejamento e execução do orçamento federal da saúde. O padrão instável de execução das emendas sugere baixa vinculação desse instrumento com processos de planejamento nacional de médio e longo prazo, e, consequentemente, a inadequação desse mecanismo para orientar investimentos que possibilitem a redução das marcantes desigualdades em saúde no país.

O segundo grupo de problemas diz respeito ao caráter das relações entre Executivo e Legislativo no processo orçamentário, expresso na execução das emendas. O padrão observado neste estudo, a princípio, é consoante com a afirmação de outros autores de que tais relações têm se pautado mais por interesses políticos particularistas dos governos e dos parlamentares do que por propósitos públicos, ou seja, têm se orientado mais pelo propósito da governabilidade do que da equidade 16,30, cabendo explorar essa hipótese por meio de novas pesquisas na área da saúde.

Noutra perspectiva, que enfoca a relação entre financiamento federal e descentralização, Souza 28 considera a possibilidade de utilização da emenda como um mecanismo redistributivo e redutor das desigualdades na capacidade de financiamento dos governos subnacionais que não são compensadas pelas transferências regulares e automáticas previstas no sistema de partilha fiscal brasileiro. No entanto, no caso da saúde, a escassez de recursos de investimento e a iniquidade das condições de financiamento descentralizado do SUS 31 permitem questionar sua efetividade como mecanismo compensatório para o financiamento da política.

No âmbito da saúde, as emendas também geram tensões para a distribuição dos recursos pelas regiões (estados e municípios), mobilizando Executivo e Legislativo locais. O orçamento federal da área, apesar de robusto, volta-se principalmente para o custeio das ações e serviços de saúde, com grande dependência dos estados e municípios às transferências federais do SUS para a manutenção das redes locais de atenção 31 . Além disso, permanecem restrições ao financiamento da saúde, especialmente no que concerne aos investimentos, limitados e, muitas vezes, atrelados a projetos federais específicos que podem não atender a diversidade de necessidades dos sistemas locais 28. Em síntese, as emendas podem ser importantes para o planejamento e a gestão da saúde nos estados e municípios, porque incidem sobre a distribuição e disputa para a obtenção de recursos de investimento, que têm sido historicamente escassos.

Existe uma tensão inerente ao duplo caráter das emendas, como recurso político e mecanismo financeiro. Por um lado, as emendas foram concebidas para introduzir maior balanceamento entre os Poderes e possibilitar a entrada de demandas loco-regionais no orçamento federal, expressando variadas lógicas para a distribuição de recursos nem sempre coerentes com o planejamento setorial. Por outro lado, a emenda é também um recurso financeiro do sistema que interfere na execução das ações e, a princípio, deveria estar inserida em uma lógica mais geral de planejamento. Contudo, as tentativas de orientação programática desse recurso podem colidir com o propósito original de criação desse mecanismo.

Não por acaso, há conflitos entre a utilização das emendas como instrumento político das relações entre Executivo e Legislativo, e/ou dos parlamentares com suas bases eleitorais, e a necessidade de orientar a apresentação de 
emendas parlamentares por processos de planejamento que considerem as prioridades da saúde coletiva.

Esse debate sugere a importância do aprimoramento das relações entre Executivo e Legislativo (nacional, estadual e municipal), de modo a estabelecer prioridades de investimento que não venham a prejudicar o funcionamento do sistema, mas que também possam atender as demandas locais. As negociações entre os Poderes nesse âmbito não têm sido transparentes para a opinião pública. As dificuldades de acesso às informações detalhadas sobre a execução das emendas, registradas neste estudo, limitam o controle público sobre a destinação desses recursos.

As observações acima sugerem o que talvez seja a conclusão mais importante deste estudo: as emendas parlamentares não podem ser compreendidas apenas como um mecanismo orçamentário e de financiamento da saúde. A execução das emendas parlamentares não se explica somente por variáveis setoriais ou rela- tivas à ação planejada do Executivo Federal nem pela busca de ampliação de ações que visem à redução das desigualdades. As explicações para o caráter da execução das emendas no período estudado parecem se situar mais no plano das relações entre Poderes e da busca de construção de governabilidade para a atuação do Executivo Federal. Tal questão merece ser aprofundada por outras pesquisas que analisem o processo político e a distribuição das emendas por autoria e tipo de ação.

Atualmente, somam-se aos limites históricoestruturais do sistema de saúde dificuldades políticas, institucionais e de gestão, em um cenário de recursos escassos frente ao projeto de universalização da saúde proposto em 1988. Nesse contexto, as emendas parlamentares acirram interesses e, muitas vezes, reforçam práticas que colidem com os propósitos de fortalecimento dos investimentos federais em uma perspectiva de redução das desigualdades em saúde no país.

\section{Resumo}

O orçamento público brasileiro passou por mudanças na Constituição Federal de 1988. Instituíram-se mecanismos para integração das atividades de planejamento e orçamento, e definiram-se formas de participação do Poder Legislativo no processo orçamentário. As emendas parlamentares surgem nesse contexto. $O$ artigo discute a participação das emendas no orçamento federal da saúde no período de 1997 a 2006, reunindo elementos para a análise dos mecanismos de financiamento e planejamento setorial. Verificou-se uma participação significativa das emendas no período, reunindo mais da metade dos recursos de investimento em alguns anos. A Região Norte destaca-se pelo aporte de recursos, indicando a necessidade de estudos que aprofundem a relação entre destino de emendas e coalizões político-partidárias. Conclui-se que as emendas não podem ser compreendidas apenas como um mecanismo de financiamento, mas também como um mecanismo da política, não estando submetidas obrigatoriamente à lógica do planejamento, o que reforça a necessidade de maior transparência do poder público na execução orçamentária.

Política de Saúde; Financiamento em Saúde; Orçamentos 


\section{Colaboradores}

T. W. F. Baptista participou da concepção, análise das regras institucionais e base de dados, escrita e revisão do artigo. C. V. Machado participou da concepção, análise dos dados, escrita e revisão do artigo. L. D. Lima participou da concepção do artigo, análise dos dados, escrita e revisão do artigo. M. Garcia participou da concepção do artigo, análise das regras institucionais, escrita e revisão do artigo. C. L. T. Andrade participou da concepção do artigo, no tratamento da base de dados, escrita e revisão do artigo. C. D. Gerassi participou da concepção do artigo, tratamento da base de dados, escrita e revisão do artigo.

\section{Referências}

1. Giacomoni J. Orçamento público. São Paulo: Editora Atlas; 2001.

2. Figueiredo AC, Limongi F. Executivo e Legislativo na nova ordem constitucional. Rio de Janeiro: Fundação Getulio Vargas; 1999.

3. Figueiredo AC. Instituições e política no controle do Executivo. Dados Rev Ciênc Sociais 2001; 44:689-727.

4. Pessanha C. O poder executivo e o processo legislativo nas constituições brasileiras. In: Vianna LW, organizador. A democracia e os três poderes no Brasil. Belo Horizonte: Universidade Federal de Minas Gerais/Rio de Janeiro: Instituto Universitário de Pesquisas do Rio de Janeiro/Fundação de Amparo à Pesquisa do Estado do Rio de Janeiro; 2003. p. 141-94.

5. Rezende F, Cunha A, organizadores. Contribuintes e cidadãos. Compreendendo o orçamento federal. Programa de Estudos Fiscais. Rio de Janeiro: Editora FGV; 2002.

\section{Agradecimentos}

À Fundação Oswaldo Cruz pelo financiamento no Programa de Apoio à Pesquisa (Programa PAPES).
6. Giambiagi F, Além AC. O ajuste do Governo Central: além das reformas. In: Giambiagi F; Moreira MM, organizadores. A economia brasileira nos anos 90. Rio de Janeiro: Banco Nacional de Desenvolvimento Econômico e Social; 1999. p. 85-110.

7. Sanches O. A atuação do poder legislativo no orçamento: problemas e imperativos de um novo modelo. Revista de Informação Legislativa 1998; 35:5-23.

8. Brasil. Resolução №. 1, de 1991, do Congresso Nacional. Dispõe sobre a Comissão Mista Permanente a que se refere o $\$ 1$ o do art 166 da Constituição Federal. Brasília. Diário Oficial do Congresso Nacional 1991; 18 mai.

9. Brasil. Resolução №. 2, de 1995, do Congresso Nacional. Dispõe sobre a Comissão Mista Permanente a que se refere o $\S 1$ o do art 166 da Constituição e sobre a tramitação das matérias a que se refere o mesmo artigo. Diário Oficial da União 1995 05 mai. 
10. Brasil. Resolução no. 1, de 2001, do Congresso Nacional. Dispõe sobre a Comissão Mista Permanente a que se refere o $\$ 1$ lo do art 166 da Constituição e sobre a tramitação das matérias a que se refere o mesmo artigo. Diário Oficial da União 2001; 08 out.

11. Brasil. Resolução no. 1, de 2003 do Congresso Nacional. Dispõe sobre a Comissão Mista Permanente a que se refere o $\S 1$ o do art 166 da Constituição e sobre a tramitação das matérias a que se refere o mesmo artigo. Diário Oficial da União 2003; 21 ago.

12. Brasil. Resolução no. 1, de 2006, do Congresso Nacional: Dispõe sobre a Comissão Mista Permanente a que se refere o $\S 1$ 1o do art 166 da Constituição e sobre a tramitação das matérias a que se refere o mesmo artigo. Diário Oficial da União 2006; 26 jul.

13. Baptista TWF, Garcia M, Lima LD, Machado CV, Andrade CLT. O orçamento federal e as emendas parlamentares da saúde no PPA 2004-2007: uma discussão a partir das regras institucionais. In: Melamed C, Piola SF, organizadores. Políticas públicas e financiamento federal do Sistema Único de Saúde. Brasília: Instituto de Pesquisa Econômica e Aplicada; 2011.

14. Rezende F, Cunha A. O orçamento público e a transição do poder. Rio de Janeiro: Editora FGV; 2003.

15. Bezerra MO. Em nome das "bases". Política, favor e dependência pessoal. Rio de Janeiro: Editora Relume-Dumará; 1999.

16. Pereira C, Mueller B. Comportamento estratégico em presidencialismo de coalizão. As relações entre executivo e legislativo na elaboração do orçamento brasileiro. Dados Rev Ciênc Sociais 2002; 45:265-301.

17. Amorim Neto O, Santos F. A conexão presidencial. Facções pró e antigoverno e disciplina partidária no Brasil. Dados Rev Ciênc Sociais 2001; 44:291321.

18. Souza C. Políticas públicas e orçamento público. Conflitos e cooperação. In: Benevides MV, Kerche F, organizadores. Reforma política e cidadania. São Paulo: Editora Fundação Perseu Abramo; 2003. p. 134-61.

19. Cintra AO. O sistema de governo no Brasil. In: Avelar L, Cintra AO, organizadores. Sistema político brasileiro: uma introdução. Rio de Janeiro: Fundação Konrad-Adenauer-Stiftung/São Paulo: Fundação Unesp; 2004. p. 59-79.
20. Senado Federal. Sistema SIGA Brasil. http://www9. senado.gov.br/portal/page/portal/orcamento_se nado (acessado em 02/Fev/2011).

21. Krieger G, Rodrigues F, Bonassa EC. Os donos do congresso: a farsa na CPI do Orçamento. Rio de Janeiro: Editora Ática; 1994.

22. Congresso Nacional. Relatório dos trabalhos da CPMI “das ambulâncias". Brasília: Congresso Nacional; 2006.

23. Machado CV. O modelo de intervenção do Ministério da Saúde brasileiro nos anos 90. Cad Saúde Pública 2007; 23:2113-26.

24. Sallum Jr. B. Metamorfoses do Estado brasileiro no final do século XX. Rev Bras Ciênc Soc 2003; 18: 35-54.

25. Presidência da República. Brasil 1994-2002: a era do real - Projeto Alvorada: ação onde o Brasil é mais pobre. Brasília: Presidência da República; 2002.

26. Machado CV. Direito universal, política nacional: o papel do Ministério da Saúde na política de saúde brasileira de 1990 a 2002. Rio de Janeiro: Editora do Museu da República; 2007.

27. Santos MHC. Governabilidade, governança e democracia: criação de capacidade governativa e relações executivo-legislativo no Brasil pós-constituinte. Dados Rev Ciênc Sociais 1997; 30:335-76.

28. Souza C. Federalismo e conflitos distributivos: disputa dos estados por recursos orçamentários federais. Dados Rev Ciênc Sociais 2003; 46:345-84.

29. Machado CV. Prioridades de saúde no Brasil nos anos 1990: três políticas, muitas lições. Rev Panam Salud Pública 2006; 20:44-9.

30. Oliveira PTR. O Sistema Único de Saúde, descentralização e a desigualdade regional: um enfoque sobre a Região da Amazônia Legal [Tese de Doutorado]. Rio de Janeiro: Escola Nacional de Saúde Pública Sergio Arouca; 2005.

31. Lima LD. Federalismo, relações fiscais e financiamento do Sistema Único de Saúde: a distribuição de receitas vinculadas à saúde nos orçamentos municipais e estaduais. Rio de Janeiro: Museu da República; 2007.

Recebido em 12/Abr/2011

Versão final reapresentada em $02 / \mathrm{Jul} / 2012$

Aprovado em 29/Ago/2012 